\title{
Assessment of Power Quality in a Microgrid with Power Electronic Converters
}

\author{
P. M. Ivry ${ }^{1}$, D.W.P. Thomas ${ }^{2}$, and M.Sumner ${ }^{3}$ \\ Electrical Systems and Optics Research Division \\ University of Nottingham \\ Nottingham, UK \\ 12preyeivry@mail.ndu.edu.ng; ${ }^{2}$ dave.thomas@nottingham.ac.uk; ${ }^{3}$ mark.sumner@nottingham.ac.uk
}

\begin{abstract}
This paper highlights the importance of assessing Power Quality (PQ) of microgrids using the recommended indices as stated in IEEE 519 and IEEE 1547 standards. It assesses the microgrid $P Q$ by verifying if converter harmonics at the Point of Common Coupling (PCC) to the grid complies or exceeds the IEEE 519 standard on harmonic limit.
\end{abstract}

Keywords-Microgrid; Power Quality; Power Electronic Converter; Total Demand Distortion (TDD; Total Harmonic Distortion (THD)

\section{INTRODUCTION}

Microgrids can be defined as a coordinated controlled close assemblage of small Distributed Energy Resource (DER) generators, storage devices and loads for optimizing the use of renewable or alternative energy generation while connected or disconnected from the main Electric Power System (EPS) [1].

On the other hand, Power Quality (PQ), is the measure, analysis and improvement of an EPS voltage and current to maintain a sinusoidal waveform at rated values and frequency that results in the proper operation of all electrical devices on the EPS.

In recent years, the PQ of microgrids have become a cause of concern because of the harmonics generated by the increased use of power electronic converters usually utilized to integrate Renewable Energy Sources (RES) to the EPS. These harmonics affect PQ and may cause damage or malfunction of the EPS or equipment on the EPS [2].

An appropriate assessment of power quality in microgrids based on harmonic distortion levels should entail that the microgrid complies with the IEEE 519 harmonic standard [3] and the IEEE 1547 standard for interconnecting Distributed Resource with Electric Power Systems [4]. These two standards requires the voltage harmonic levels to be estimated using the Total Harmonic Distortion (THD) in (1) while the harmonic distortion levels for current be measured using the Total Demand Distortion (TDD) indices in (2).

$$
T H D=\frac{\sqrt{\sum_{h>1}^{h_{50}} V_{h}^{2}}}{V_{1}} \times 100 \%
$$

$$
T D D=\frac{\sqrt{\sum_{h>1}^{h_{50} I_{h}^{2}}}}{I_{D \_ \text {max }}} \times 100 \%
$$

In [3], THD is defined as "the ratio of the root mean square of the harmonic content, considering harmonic components up to the 50th order and specifically excluding interharmonics, expressed as a percent of the fundamental". It was further stated in [3] that "harmonic components of order greater than 50 may be included when necessary".

TDD was also defined in [3] as "the ratio of the root mean square of the harmonic content, considering harmonic components up to the 50th order and specifically excluding interharmonics, expressed as a percent of the maximum demand current $\left(I_{D_{-} \max }\right)$. Harmonic components of order greater than 50 may be included when necessary".

Notwithstanding it is almost common practice to measure current and voltage harmonics using the THD indices. This is evident in most common power system simulation softwares and industrial power quality measuring devices [2, 5]. Even many authors have presented literatures estimating current and voltage harmonics in THD. This discrepancy or oversight maybe due to the following reasons;

1) Unification and Ease of using one measuring indices (THD).

2) Difficulty in estimating maximum current demand at the design stage of an EPS [5, 6].

3) Or simply because THD approximately equals TDD when an EPS is operating at the maximum rated power $[5,6]$.

Solutions have been given to the second stated reason in some literatures [6, 7] and the IEEE 1547 standard [4] recommends that the Total Rated-Current Distortion (TRD) can be used in place of the TDD during the design stage. Irrespective of whatever reason, it is the view of the authors that the correct indices for estimating current harmonics should henceforth be implemented in assessing microgrid power quality.

$$
T R D=\frac{\sqrt{\sum_{h>1}^{h_{50}} I_{h}^{2}}}{I_{\text {rated }}} \times 100 \%
$$


This paper aims to highlight the difference between the THD and TDD and hence emphasize the importance of assessing power quality using the appropriate indices. As using an improper indices might give a conservative answer or a false cause of concern. An assessment of a microgrid PQ would be carried out by checking if the power electronic converter harmonics as seen at the Point of Common Coupling (PCC) to the grid complies with the IEEE 519 harmonic limit standard and the IEEE 1547 standard. The voltage harmonics will be analyzed using the THD while the current harmonic will be analyzed using the THD and the Total Demand Distortion (TDD).

\section{STUdied CONVERTER AND MICROGRID}

\section{A. Converter Design and Specifications}

Sinusoidal Pulse Width Modulated, PI controlled 3-phase 2-level Voltage Source Converters (VSCs) are designed and analyzed due to their widely accepted capability. The parameters are given in Table I.

TABLE I. VSC SPECIFICATION

\begin{tabular}{|c|c|}
\hline Parameters & Values \\
\hline Power & $12.5 \mathrm{~kW}$ \\
\hline Voltage & $415 \mathrm{~V} / 50 \mathrm{~Hz}$ \\
\hline Switching Frequency & $2 \mathrm{kHz}$ \\
\hline DC Voltage & $905 \mathrm{~V}$ \\
\hline Amplitude Modulation & 0.8 \\
\hline
\end{tabular}

\section{B. Microgrid Design}

The microgrid comprises of 2 Photovoltaic (PV) system with voltage source inverters and 1 Wind Turbine (WT) system having a back-to back VSC. The microgrid is connected to the EPS and also supplies a small amount of linear and non-linear loads (see Fig. 1).

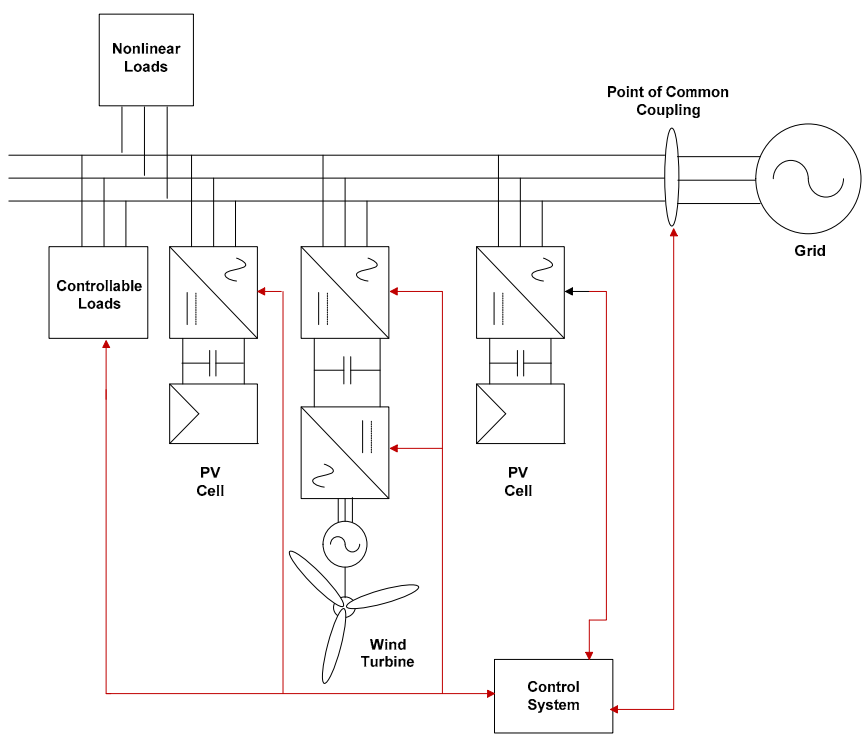

Fig. 1. Schematics of Simulated Microgrid

\section{RESULTS}

The power output of the VSCs are varied from the rated $12.5 \mathrm{~kW}$, to $66 \%$ rated and $33 \%$ rated as recommended in the IEEE 1547 standard. This is done to reflect the variability of generated power of RES in microgrids and to highlight the difference of values estimated using the THD and TDD.

\section{A. Rated Power $(12.5 \mathrm{~kW})$}

At full rated power the current THD $\left(\mathrm{THD}_{\mathrm{i}}\right)$ and TDD are the same [6]. The voltage THD $\left(\mathrm{THD}_{\mathrm{v}}\right)$ was $4.80 \%$. From Figs. 2 and 3 it is clear that the THD, THD $_{i}$ and current TDD are within the IEEE 519 harmonic limit.

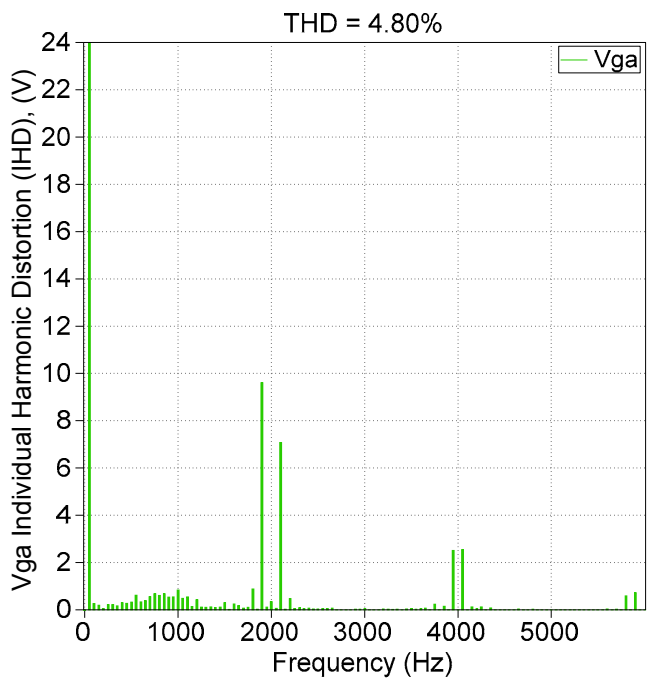

Fig. 2. Voltage $\mathrm{THD}_{\mathrm{v}}$ at the PCC (Rated Power)



Fig. 3. Current $\mathrm{THD}_{\mathrm{i}}$ and TDD at the PCC (Rated Power)

\section{B. $66 \%$ Rated Power $(8.25 \mathrm{~kW})$}

For $66 \%$ rated power, the $\mathrm{THD}_{\mathrm{v}}$ was $4.70 \%$, implying a small reduction from the $\mathrm{THD}_{\mathrm{v}}$ at rated power. The $\mathrm{THD}_{\mathrm{v}}$ was barely affected by output power variation, so only the current $\mathrm{THD}_{\mathrm{i}}$ and TDD graphs are presented in Fig. 4. The current THD $_{\mathrm{i}}$ and TDD presented in Fig. 4 had different values. While the TDD gives a reduced current distortion value, the $\mathrm{THD}_{\mathrm{i}}$ had 
an increase. In this case both the current $\mathrm{THD}_{\mathrm{i}}$ and TDD were still within the IEEE 519 harmonic limit.

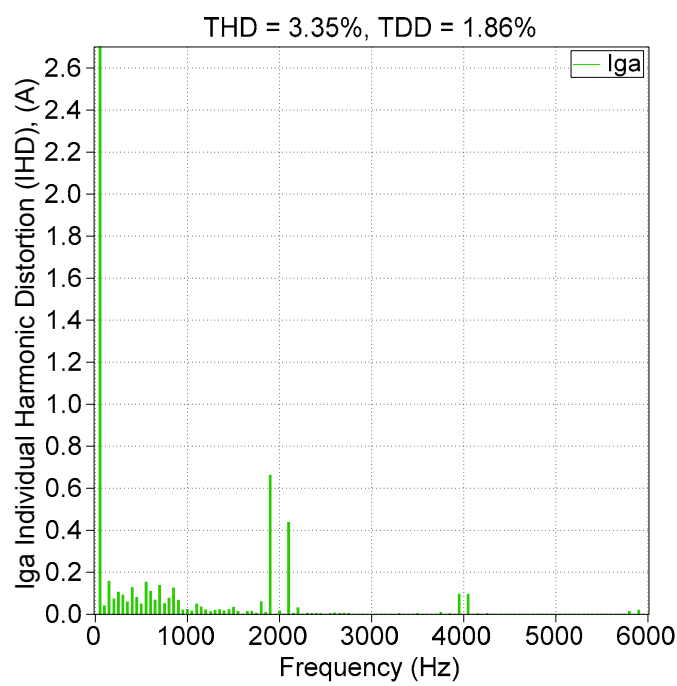

Fig. 4. Current $\mathrm{THD}_{\mathrm{i}}$ and TDD at the PCC (66\% Rated Power)

\section{C. $33 \%$ Rated Power $(4.125 \mathrm{~kW})$}

In this case, the $\mathrm{THD}_{\mathrm{v}}$ was $4.67 \%$, this is also close to the first two cases. For the current, it can be seen that the TDD had a further reduction and easily complies with the IEEE 519 harmonic limit (see Fig. 5). However, using the $\mathrm{THD}_{\mathrm{i}}$ indices presents a distortion value that fails to meet the IEEE 519 harmonic limit.

A case like this is paramount in discussing the importance of using the appropriate harmonic distortion indices. This is because the value given by the $\mathrm{THD}_{\mathrm{i}}$ indices presents a false cause of concern on the microgrid. Which may lead to extra cost in procuring or upgrading harmonic filters or unfair fines for private microgrid operators.

When the output power reduces in the microgrid, the current flow reduces and hence, a corresponding reduction is observed in the individual current harmonics amperage on the system. Comparing this with the fundamental current $\left(\mathrm{I}_{1}\right)$ will definitely give a high $\mathrm{THD}_{\mathrm{i}}$ making it appear as if the microgrid is injecting more harmonics. This gives a false cause of concern as in reality the ampere levels of the individual harmonic currents have been reduced. However, using the TDD gives a fair comparison between the individual current harmonic values and the maximum/rated current of the system. Thus as the microgrid output power reduces a proportionate reduction is observed for the current TDD indicating less harmonic impact on the system.

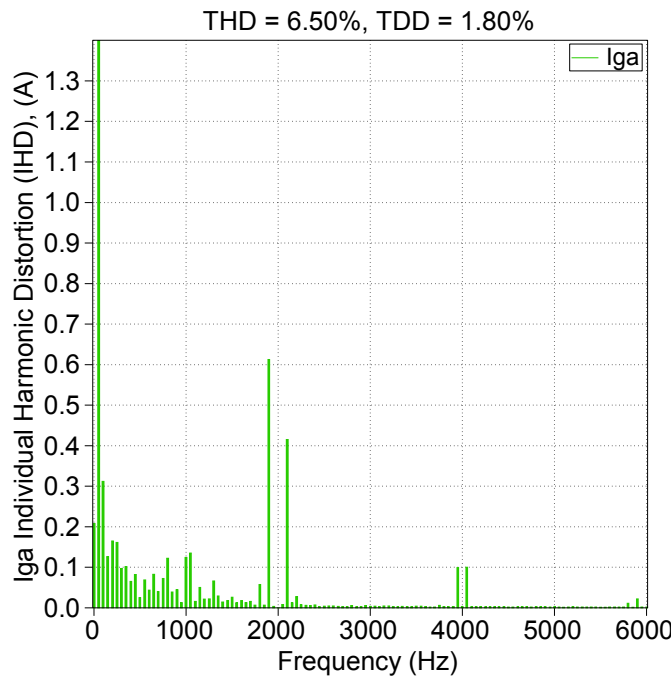

Fig. 5. Current $\mathrm{THD}_{\mathrm{i}}$ and TDD at the PCC (33\% Rated Power)

\section{CONCLUSION}

A case study has been presented to highlight the importance of assessing power quality of microgrids using the appropriate harmonic distortion indices as recommended by the IEEE 519 and IEEE 1547 standards. The simulated study clearly shows that measuring current harmonics using the $\mathrm{THD}_{\mathrm{i}}$ instead of the TDD gives results that may not comply with the IEEE 519 and 1547 standards. In a practical microgrid, this noncompliance might lead to extra cost in harmonic filters. On the other hand conservative results would be achieved if the standard is met using $\mathrm{THD}_{\mathrm{i}}$ as in theory $\mathrm{I}_{\text {rated }}$ is greater than $\mathrm{I}_{1}$ at reduced power. Meanwhile, the microgrid current TDD indices would be very well within the harmonic standards if the standard is met using $\mathrm{THD}_{\mathrm{i}}$.

To encourage the use of the correct indices in research, simulation software companies should include a TDD/TRD measuring block and manufacturers of power quality analyzers should include the TDD/TRD in its log of data.

\section{REFERENCES}

[1] R. H. Lasseter, "Smart Distribution: Coupled Microgrids," Proceedings of the IEEE, vol. 99, pp. 1074-1082, 2011.

[2] P. Salmeron, R. S. Herrera, A. P. Valles, and J. Prieto, "New Distortion and Unbalance Indices Based on Power Quality Analyzer Measurements," Power Delivery, IEEE Transactions on, vol. 24, pp. 501-507, 2009.

[3] "IEEE Recommended Practice and Requirements for Harmonic Control in Electric Power Systems," IEEE Std 519-2014 (Revision of IEEE Std 519-1992), pp. 1-29, 2014.

[4] "IEEE Standard for Interconnecting Distributed Resources with Electric Power Systems," IEEE Std 1547-2003, pp. 1-28, 2003.

[5] T. M. Blooming and D. J. Carnovale, "Application of IEEE STD 5191992 Harmonic Limits," in Pulp and Paper Industry Technical Conference, 2006. Conference Record of Annual, 2006, pp. 1-9.

[6] T. Hoevenaars, K. LeDoux, and M. Colosino, "Interpreting IEEE STD 519 and meeting its harmonic limits in VFD applications," in Petroleum and Chemical Industry Conference, 2003. Record of Conference Papers. IEEE Industry Applications Society 50th Annual, 2003, pp. 145-150.

[7] S. Vlahinic, D. Brnobic, and N. Stojkovic, "Indices for Harmonic Distortion Monitoring of Power Distribution Systems," Instrumentation and Measurement, IEEE Transactions on, vol. 58, pp. 1771-1777, 200 